\title{
Urtarokobiltegiratze termikoko sistemen bideragarritasun tekno-ekonomikoaren azterketa
}

\author{
Technical and economic feasibility analysis of Seasonal \\ Thermal Energy Storage system
}

\author{
Oihane Setién Echenique* \\ Tecnalia Gela, UPV/EHU \\ Carol Pascual Ortiz** \\ Energia eta Ingurumeneko Saila, Tecnalia \\ *osetien001@ikasle.ehu.eus \\ **carol.pascual@tecnalia.com
}

DOI: $10.1387 /$ ekaia.15854

Laburpena: Gaur egun, Europako energiaren kontsumo osoaren \%40 eraikinek eragiten dute.Kontsumo horren barnean, eraikinetako berokuntza eta ur bero sanitarioaren (UBS) erabilera nabarmentzen da, batik bat. Espainiaren kasuan, berokuntza \%50 da, eta UBSa, berriz, \%27.

Proiektu honen bitartez, Espainia mailan Urtarokobiltegiratze termikoko sistemen (STES)bideragarritasun ekonomiko zein energetikoa aztertu da. Espainiako hainbat hiritako eskari termikoak simulatu dira, eta STESaren bitartez berogailuko eta UBSko eskari osoaren \%45-60 artean asetzeko saiakera egin da. Beraz, ikusita eraikinetan kontsumo energetiko handia izaten dela, eta, gainera,jakinda Eraikuntzarako Kode Teknikoak (CTE) ur bero sanitariorako eguzki-energia termikoaren kontribuzio minimoa derrigortzen duela, sistema horien bideragarritasunaren azterketa ezinbestekoa da. Hala, energia berriztagarrien erabilera sustatzen da.

Hitz gakoak: Urtaroko biltegiratze termikoko sistema,STES, eguzki-energia termikoa, energia berriztagarria.

Abstract: The energy use of buildings accounts for roughly $40 \%$ of the total energy consumption in the European Union. In Spain the space heating represents the 50\%, while the domestic hot water represents the $27 \%$ of the total consumption.

The aim is to analyze the economic and energetic viability of seasonal thermal energy storages in Spain. For this purpose, different energy demands will be simulated in 
different cities of Spain, with the aim of satisfying the $45-60 \%$ of the total demand. Moreover, as dictated by the Spanish Technical Building Code (CTE), part of the demand of DHW must be satisfied by solar thermal energy. Therefore, the viability analysis of a STES is essential to promote the use of renewable energies.

Keywords: Seasonal Thermal Energy Storage, STES, solar thermal energy, renewable energy.

\section{SARRERA}

Gaur egun,Europako energiaren kontsumo osoaren \%40 eraikinek eragiten dute. Eraikinetan berokuntza eta ur bero sanitarioaren erabilerak nabarmentzen dira batik bat $[1,2]$. Espainiaren kasuan, ur bero sanitarioaren kontsumoa $\% 27$ da, eta berokuntza, aldiz, $\% 50$.

\section{ESPAINIAKO KLIMATOLOGIA}

Espainian hainbat gune klimatiko daude; letra batez eta zenbaki batez adierazten dira. Letrak neguko klimaren gogortasunari (Severidad Climática de Invierno, SCI) dagozkio; zenbakiak, berriz, udako klimaren gogortasunari (Severidad Climática de Verano, SCV).

Bestetik, Eraikuntzarako Kode Teknikoaren (CTE) HE4 dokumentuaren arabera, ur bero sanitariorako eguzki-energia termikoaren kontribuzio minimo bat eduki behar da. Horretarako, Espainian eguneko eguzki-erradiazio osoaren araberako hainbat gune definitu dira.

1. irudian Espainiako gune klimatikoak eta erradiazioa ikus daitezke:
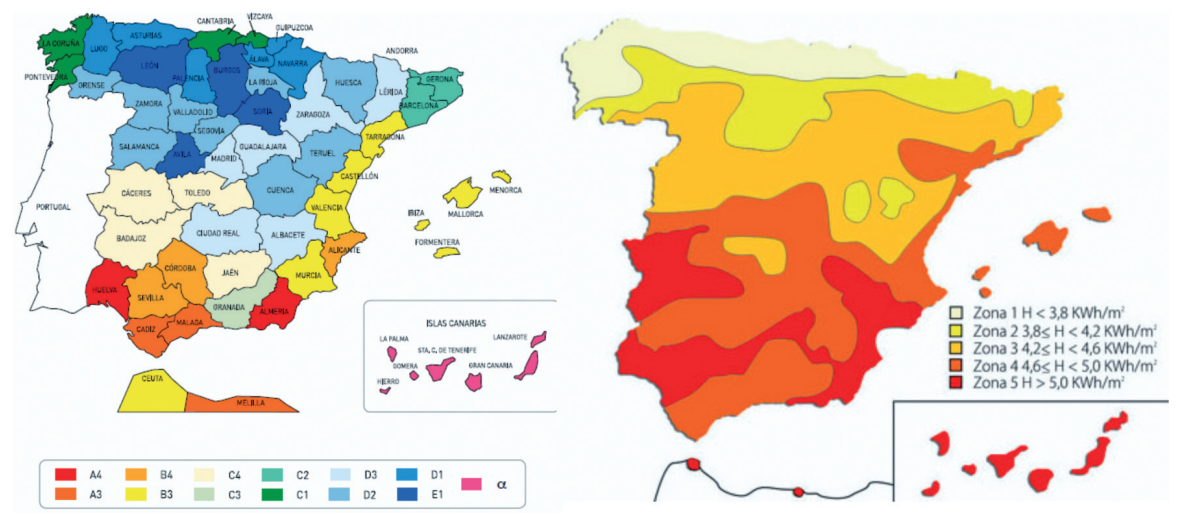

1. irudia. Espainiako gune klimatikoak eta erradiazioa [3]. 


\section{URTAROKO BILTEGIRATZE TERMIKOKO INSTALAZIOAK (STES)}

Eguzki-energia termikoa indar handia hartzen ari da, ur bero sanitariorako (UBS) eta berokuntzarako erabiltzen dabatik bat. Gaur egun, eguzkienergia termikoaren aplikazio nagusia etxeko erabilera da. Etxeko sistemetan hiru mota bereiz daitezke [4]:

- Eguzkitiko ur bero sanitarioa (SDHW: Solar Domestic Hot Water), eguzkia erabiltzen da soilik ur beroa lortzeko.

- Eguzki-sistema konbinatua (SDHW\&H: Solar Domestic Hot Water \& Heating): eguzki-beroa erabiltzen da ur berorako eta tokiko beroketarako.

- Igerileku-sistemak, zeinetan eguzkia erabiltzen den horiek berotzeko.

Urtaroko biltegiratze termikoko sistema (STES: Seasonal Thermal Energy Storage) udako hilabeteetan eguzki-energia termikoa (beroa) biltegiratzean datza, ondoren, neguko hilabeteetan erabiltzeko helburuarekin.

Izan ere, udan, eguzki-energia termiko gehiagobiltegira dezakegu neguan baino. Gainera, urteko bero-eskari ia guztia neguan izaten da; hau da, udan ia ez dago bero-eskaririk. Bi arrazoi horiek kontuan hartuta, 2. irudian ageri den bezala, udan (apiriletik hasita urrira arte) sobera daukagun eguzki-energia termikoa biltegiratuko dugu, eta, hala, neguko bero-eskariak aseko ditugu.

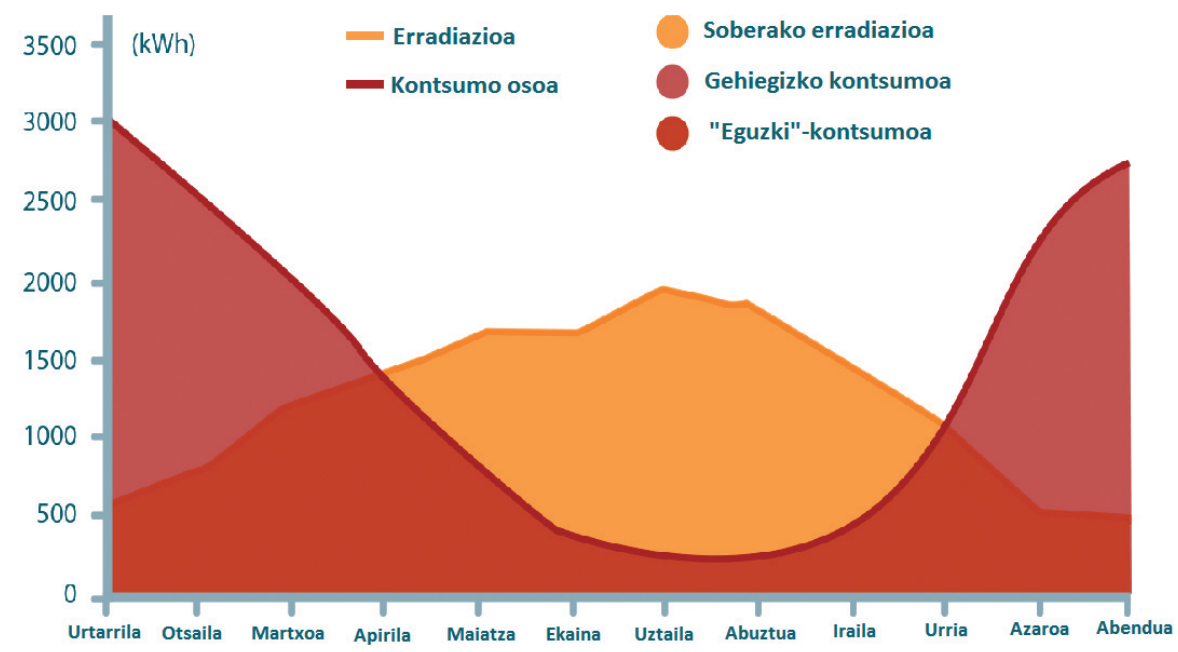

2. irudia. bero-eskaria eta eguzki-energia termikoa $(\mathrm{kWh})[5]$. 
Urtaroko biltegiratze termikoko sistema batean oinarritutako instalazio batek honako azpisistema hauek ditu (3. irudia).

- Bero-sorrera.

- Urtaroko biltegiratze termikoko sistema.

- Ur beroko banaketa-sistema.

- Sistema laguntzailea.

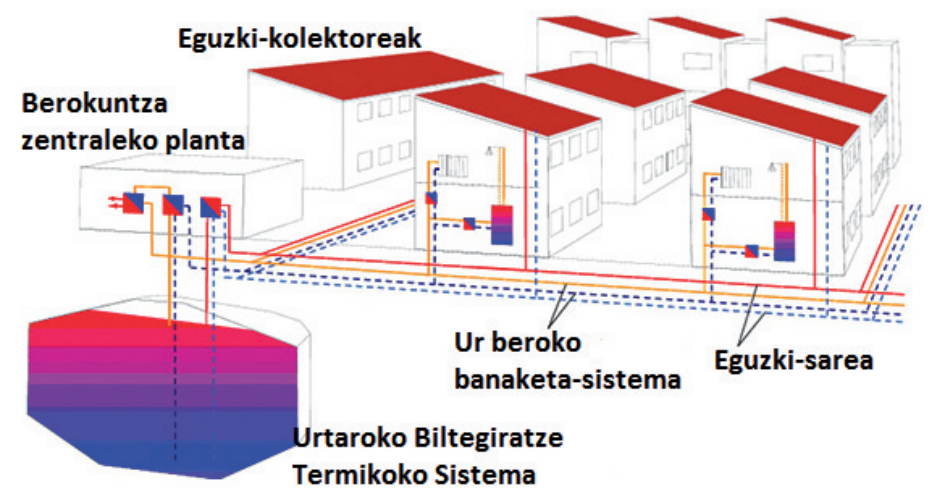

3. irudia. STES sisteman oinarritutako instalazioa [1].

Lau STES mota bereizten dira (4. irudia) [1,2]:

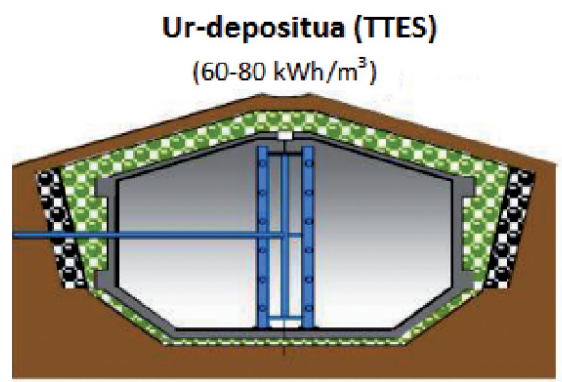

Biltegiratze geotermikoa (BTES)

$\left(15-30 \mathrm{kWh} / \mathrm{m}^{3}\right)$

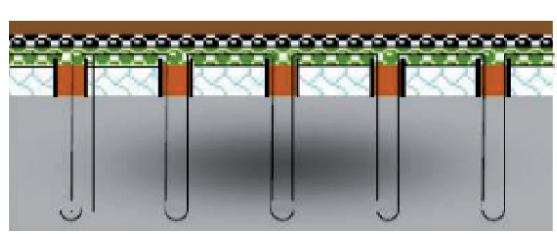

4 irudia. STES sistema ezberdinak[1].
Putzuko biltegiratzea (PTES)

$\left(60-80 \mathrm{kWh} / \mathrm{m}^{3}\right)$

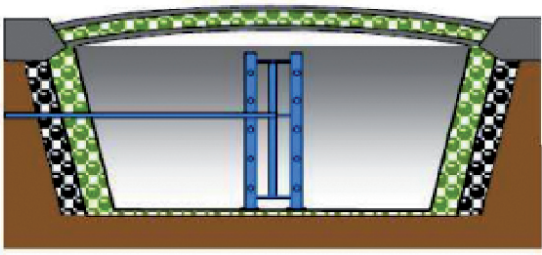

Akuiferoak (ATES)

$\left(30-40 \mathrm{kWh} / \mathrm{m}^{3}\right)$

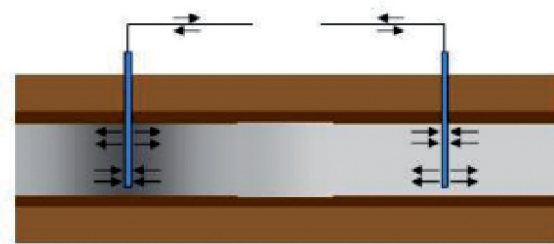


- Ur-depositua (TTES: Tank Thermal Energy Storage). Lurperatuta dagoen hormigoizko ur-tanga. Termodinamikoki egokiena, baina baita garestiena ere. Lur mota gehienetara moldatzen da.

- Putzuko biltegiratzea (PTES: Pit Thermal Energy Storage). Putzu artifiziala, estalki baten bitartez ixten dena. Putzua urez edo urlegar nahasketaz bete daiteke.

- Biltegiratze geotermikoa (BTES: Borehole Thermal Energy Storage). Beroa zuzenean lurrean biltegiratzen da, ez dago biltegi fisikorik, eta bero-trukaketa bertikalki lurperatutako hodi batzuen bitartez egiten da.

- Akuiferoak (ATES: Aquifer Thermal Energy Storage). Lurpean naturalki biltegiratzen den ura erabiltzen da bero-trukaketan. Akuiferoak putzu hotz eta bero banaz osatuta egongo dira.

1. taulan lau STES sistemak konparatzen dira [6]:

1. taula. STES sistemen arteko erkaketa.

\begin{tabular}{|c|c|c|c|}
\hline TTES & PTES & BTES & ATES \\
\hline \multicolumn{4}{|c|}{ Biltegiratze-baliabidea } \\
\hline Ura & Ur-legarra & Lurra/arroka & Harea-ura \\
\hline \multicolumn{4}{|c|}{ Beroaren biltegiratze-ahalmena $\left(\mathrm{kWh} / \mathrm{m}^{3}\right)$} \\
\hline $60-80$ & $30-50$ & $15-30$ & $30-40$ \\
\hline \multicolumn{4}{|c|}{$1 \mathrm{~m}^{3}$ ur betetzeko beharrezkoa den bolumena } \\
\hline $1 \mathrm{~m}^{3}$ & $1,3-2 \mathrm{~m}^{3}$ & $3-5 \mathrm{~m}^{3}$ & $2-3 \mathrm{~m}^{3}$ \\
\hline \multicolumn{4}{|c|}{ Tenperatura } \\
\hline $98^{\circ} \mathrm{C}$ & $80-90^{\circ} \mathrm{C}$ & $80^{\circ} \mathrm{C}$ & - \\
\hline \multicolumn{4}{|c|}{ Baldintza geologikoak } \\
\hline $\begin{aligned} \text { - Lurreko baldintza } \\
\text { egonkorrak } \\
\text { - Lur azpiko urik } \\
\text { gabe } \\
-5-15 \mathrm{~m} \text {-ko sako- } \\
\text { nera }\end{aligned}$ & $\begin{array}{l}\text { - Lurreko baldintza } \\
\text { egonkorrak } \\
\text { - Lur azpiko urik } \\
\text { gabe } \\
-5-15 \mathrm{~m} \text {-ko sako- } \\
\text { nera }\end{array}$ & $\begin{array}{l}\text { - Zula daitekeen lu- } \\
\text { rra } \\
\text { - Lur azpiko ura } \\
\text { - B e ro - a h a l me n } \\
\text { handia } \\
\text { - Eroankortasunter- } \\
\text { miko handia } \\
\text { - } 30-100 \text { m-ko sako- } \\
\text { nera }\end{array}$ & $\begin{array}{l}\text { - Lur azpiko urik } \\
\text { gabe edo ur-jario } \\
\text { txikiarekin } \\
\text { - Akuiferoaren lo- } \\
\text { diera: } 20-50 \mathrm{~m}\end{array}$ \\
\hline
\end{tabular}




\section{SIMULAZIOAK}

Urtaroko biltegiratze termikoko sistemen bideragarritasun teknoekonomikoa aztertzeko, lehenik eta behin, instalazioaren osagaiak zehaztu behar dira. Bideragarritasuna hainbat simulazio eginez aztertu da, distritutamaina ezberdinetako Espainiako zenbait hiritan (gune klimatikoen arabera). Horretarako, TRNSYS programa erabili dugu.

Biltegiari dagokionez, ur-depositua erabili da, lur mota gehienetara moldatzen delako, eta bero-sorrera gisaeguzki-kolektore lauak. Bestetik, bi distritu-tamaina simulatu dira;bata $1.000 \mathrm{MWh} /$ urteko eskaria duena (100-200 etxebizitza), eta bestea $10.000 \mathrm{MWh} /$ urtekoa (1.000-2.000 etxebizitza). Distritu horiek Espainiako hainbat hiritan simulatu dira (neguko klimaren gogortasun eta erradiazio ezberdinetan). Hiri horiek 2. taulan ikus daitezke:

2. taula. aukeratutako hirien SCI eta erradiazio-balioak.

\begin{tabular}{lcc|lcc}
\hline \multicolumn{1}{c}{ Hiria } & SCI & Rad & \multicolumn{1}{c}{ Hiria } & SCI & \\
\hline Albacete & D & V & Granada & C & IV \\
Badajoz & C & V & Madril & D & IV \\
Cáceres & C & V & Toledo & C & IV \\
Ciudad Real & D & IV & Zaragoza & D & IV \\
\hline
\end{tabular}

Hiri horiek erradiazio altua (IV eta V) eta urtean zehar eskari orekatua dutelako aukeratu dira, baldintza horiek baitira sistema bat instalatzeko egokienak [7]. Distrituaren tenperatura gisa $70-40^{\circ} \mathrm{C}$-rekin simulatu dugu.

\section{EMAITZAK ETA ONDORIOAK}

Ondoko 5. irudian Granadako simulazioan lortutako emaitzen bi grafiko ikus daitezke. Lehenengoan, beroaren hilabeteko balantzea irudikatzen da. Barra urdinak tangaren kargari dagozkie, eta ondo ikusten da nola doan kargatzen hilabeteetan zehar. Barra gorriek,aldiz, tangaren deskarga irudikatzen dute, eta, ikusten denez, urria eta azaroa aldera tanga asko deskargatzen da. Abenduan eta neguko hilabeteetan tangak ez dauka deskargatzeko bezainbesteko ahalmenik; baina, hala ere, tangaren bitartez eskariaren zati bat ase ahal izango da, eta falta dena galdara baten bitartez emango da. Amaitzeko, barra berdeak tangan izaten diren bero-galerei dagozkie; gutxi gorabehera \%20koak izaten dira. 
HILEROKO BERO-BALANTZEA

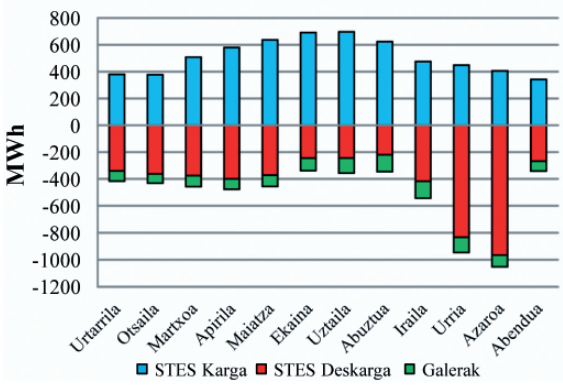

HILEROKO BALANTZEA

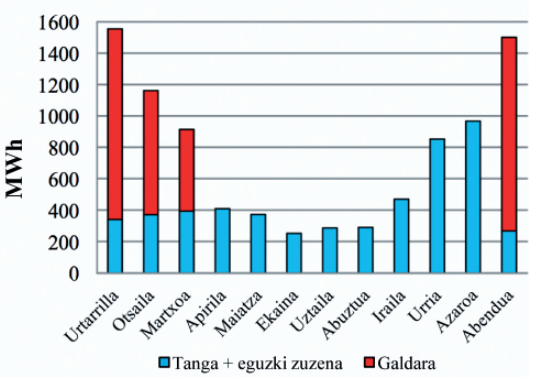

5. irudia. Beroaren balantzea eta eskaria asetzeko era.

Bigarren grafikoan, hileroko eskaria eta zeren bitartez asetzen den ikus daiteke. Barra urdinek tangaren bitartez eta eguzki-energia termikoaren erabilera zuzenaren bitartez asetzen dena irudikatzen dute; gorriek, berriz, galdararen bitartez asetzen dena. Ikusten denez, eskaririk altuenak urtarrileko eta abenduko hilabeteetan izaten dira, eta haren zatirik handiena galdararen bitartez ematen da.

Jarraian,Granadandistritu handian (10.000 MWh/urte) lortutako emaitzen grafikoak ikus daitezke (6. irudia). Lehenengo grafikoan, tangaren bolumena eta eguzki-frakzioa (SF) erlazionatzendira azalera ezberdinetarako.
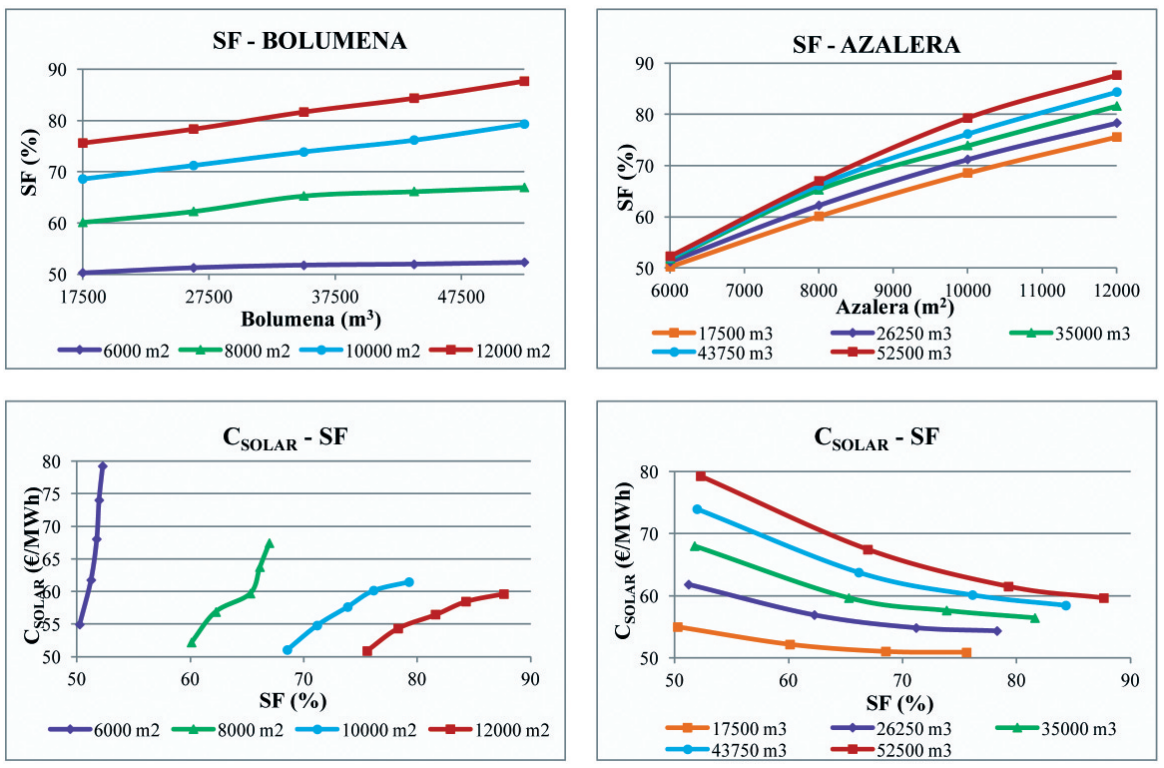

6. irudia. $10.000 \mathrm{MWh} /$ urteko distrituaren simulazioak Granadan. 
Bigarrenean, eguzki-kolektoreen azaleraren eta eguzki-frakzioaren arteko erlazioa ikusten da tangaren bolumen ezberdinetarako. Amaitzeko, azkeneko bi grafikoetan, eguzki-frakzioaren eta eguzki-beroaren kostu bateratuaren arteko erlazioa ikus daiteke; bata eguzki-kolektoreen azalera ezberdinetarako, eta bestea tangaren bolumen ezberdinetarako.

Bi distrituetan kolektoreen azalera eta tangaren bolumen ezberdinekin simulazioak eginez, hainbat ondorio atera ahal izan dira.

Instalazio batean, eguzki-kolektoreen azalera konstante baterako, tangaren bolumena aldatuz lortzen den eguzki-frakzioa, hau da, eguzki energiaren bitartez asetzen den eskariaren ehunekoa, ez da asko aldatzen (lehenengo grafikoa).Izan ere, azalera berdineko kolektoreak, xurgatutako eguzki-energia kantitate berdinarekin, ez du eragin bera izango tanga txiki edo handi batean. Adibidez, $6.000 \mathrm{~m}^{2}$-ko eta $17.500 \mathrm{~m}^{3}$-ko tangekin lortzen den eguzki-frakzioa \%50ekoa da, eta tanga $52.500 \mathrm{~m}^{3}$-ra arte handituz eguzki-frakzioa $\% 52 \mathrm{koa}$ da; soilik $\% 2$ handitzea lortu da, eguzki-kolektoreen azalera horrekin ezin baita bero gehiagorik sartu. $12.000 \mathrm{~m}^{2}$-ko azalerarekin, ordea, eguzki-frakzioa \%75etik \%87ra handitzea lortu da, baina, hala ere, ezingo da \%12 baino gehiago handitu.Alderantziz, ostera, tangaren bolumen konstante baterako, kolektoreen azalera handituz, eguzkiekarpenaren balioa nabarmenki handitzen doa (bigarren grafikoa), kolektoreen azalera handitzearekin batera tanga gehiago kargatuko delako.

Oro har, zenbat eta bolumen eta azalera handiagoak izan, orduan eta eguzki-frakzio handiagoak lortuko dira. Halaber, esan dezakegu azalerak garrantzi handiagoa duela bolumenak baino. Beraz, errentagarriagoa ateratzen da, bai ekonomikoki, baita teknologikoki ere, azaleraren tamaina handitzea bolumena baino.

Alderdi ekonomikoaren inguruan esan beharra dago distritu handia simulatzean, etxebizitza kopurua asko handitu dela, eta, hortaz, azaleraren eta bolumenaren tamainak ere bai. Ondorioz, hasierako inbertsioa eta urteko kostu osoaasko handitzen dira; dena den, eguzki-beroaren kostu bateratua asko txikitzen da MWh-ko (ikus 3. taula).

Inbertsioa berreskuratzeari dagokionez, distritu txikiaren inbertsioa 11 urtetan berreskuratzen da.Handienarena, aldiz, azkarrago; 7 urtetan, alegia. Beraz, zenbat eta distritu handiagoa izan, orduan eta inbertsio handiagoa egin beharko da, baina horrek geroz eta onura gehiago dakartza.

Emaitzei erreparatuz, esan daiteke errentagarriago ateratzen dela distritu handiko instalazio bat eraikitzea. Distritu txikian eguzki-beroaren kostu bateratua merkatuan dagoen gas naturala baino garestiagoa ateratzen da $\left(\mathrm{C}_{\text {SOLAR }}>\right.$ prezioa GAS NATURALAREN AZKENEKOERABILTZAILEA $\rightarrow 0,13 € /$ $\mathrm{kWh}>0,07 € / \mathrm{kWh})$, eta hori ez da bideragarria ateratzen azkeneko erabiltzailearentzat. Hala ere, distritu txikia interesgarri suerta dakioke kontzien- 
3. taula. Granadako bi distrituen arteko erkaketa.

\begin{tabular}{lcc}
\hline & $1.000 \mathrm{MWh} / \mathrm{y}$ & $10.000 \mathrm{MWh} / \mathrm{y}$ \\
\hline Etxebizitza kopurua & 174 & 1740 \\
Eguzki-ekarpena (SF) $(\%)$ & 55,49 & 60,11 \\
Azalera $\left(\mathrm{m}^{2}\right)$ & 600 & 8000 \\
Bolumena (m $\left.{ }^{3}\right)$ & 3000 & 17500 \\
Inbertsioa (€) & 1.151 .158 & 5.009 .610 \\
Urtekokostua (Z) $(€ /$ urte) & 66.720 & 313.564 \\
$\mathrm{C}_{\text {SOLAR }}(€ / \mathrm{kWh})$ & 0,12024 & 0,05216 \\
Payback (urtea) & 11 & 7 \\
\hline
\end{tabular}

tzia berdea duen komunitate bati, bere kabuz egiten badu, nahiz eta prezioz garestiagoa izan, gas natural gutxiago erabiltzen duelako. Halaber, instalazio mota hau distritu txiki baterako ere interesgarria izango litzateke etorkizun batean, gas naturalaren prezioa igotzen bada.

\section{BIBLIOGRAFIA}

[1] Effective Integration of Seasonal Thermal Energy Storage Systems in Existing Buildings (EINSTEIN project). (2011).

[2] Desarrollo de Nuevo Concepto de Instalación Térmica Basada en el Almacenamiento Térmico Estacional para Reducción Drástica del Consumo Energético en Edificios (Berotuz). (2012).

[3] Rockwool. Nuevo Código Técnico de la Edificación DB-HE. Guía de los principales cambios.

[4] Streicher, W., Bales, C. (2005). 5. Combistores. In Hadrorn, J-C. (Ed.), Thermal energy storage for solar and low energy buildings (p. 29-40).

[5] COMTES. ThermalStorage: http://comtes-storage.eu/home/seasonal-heatstorage/

[6] Schmidt, T. Large-Scale Thermal energy Storage. Solites.

[7] de Guadalfajara Pinilla, M. (2013). Evaluación de centrales solares térmicas con acumulación estacional para el sector residencial en España (Proyecto de fin de máster): https://zaguan.unizar.es/record/10314?ln=es\# 